\title{
MUTU BIBIT MANGLID (Manglieta glauca BI) PADA TUJUH JENIS MEDIA SAPIH
}

\author{
Seedling Quality Index of Manglieta glauca BI \\ on Seven Types of Transplanting Media \\ Aris Sudomo
${ }^{1)}$, Encep Rachman
Balai Penelitian Kehutanan Ciamis \\ Jl. Raya Ciamis Banjar Km. 4, Ds. Pamalayan, Ciamis 46201 \\ Telp. (0265) 771352 Fax. (0265) 775866 \\ ${ }^{2)}$ Pusat Penelitian dan Pengembangan Peningkatan Produktivitas Hutan \\ Kampus Balitbang Kehutanan, Jl. Gunung Batu No. 5 Bogor 16610 \\ Telp. (0251) 8631238, Fax. (0251) 7520005
}

Naskah masuk : 19 Desember 2009 ; Naskah diterima : 15 November 2010

\begin{abstract}
The objective of this research was to find out the transplanting media which is able to promote the best growth and quality of Manglieta glauca BI seedling. The experiment was conducted at the nursery of Ciamis Forestry Research Institute (CiFRI), started from February to September 2008 by using Complete Random Design (CRD). There were seven types of transplanting media, namely M1 (soil + compost (3:1)), M2 (soil), M3 (soil + compost + rice shell (1:1:1)), M4 (soil + compost + sand (1:1:1)), M5 (soil + compost + cocopeat (1:1:1)), M6 ((soil + compost + saw dust (1:1:1)), and M7 (soil + compost + burned rice shell (1:1:1)). Each treatment was applied to 60 seedlings, so that the required seedlings were $7 \times 60=$ 420 seedlings. The result shows that M4 media gave better growth responses than others as follow: 0.469 $\mathrm{cm}$ of diameter's growth, $22.678 \mathrm{~cm}$ of height, and 9.978 of leave number. The M5 gave better responses than others in the following things: 2.096 of root's biomass, 4.046 of stem's and leaf's weight, and 0.132 of seedling quality index. These are the best result than the others. It is concluded that that the use of media mix M4 and M5 gave the best seedling growth and its quality index in Manglieta glauca BI.
\end{abstract}

Keywords: Manglieta glauca BI, transplanting media and seedling quality index

\begin{abstract}
ABSTRAK
Tujuan penelitian ini adalah untuk mengetahui jenis media sapih yang mampu menghasilkan pertumbuhan dan mutu bibit Manglieta glauca BI terbaik. Penelitian dilakukan di persemaian Balai Penelitian Kehutanan Ciamis dari bulan Februari 2008 s/d September 2008. Rancangan yang digunakan dalam penelitian ini adalah Rancangan Acak Lengkap (RAL) dengan 7 jenis media sapih yaitu M1 (Tanah + Pupuk kandang (3:1)), M2 (Tanah), M3 (Tanah + Pupuk kandang + Sekam padi $(1: 1: 1))$, M4 (Tanah + Pupuk kandang + Pasir (1:1:1)), M5(Tanah + Pupuk kandang + Serbuk sabut kelapa (1:1:1)), M6 ((Tanah + Pupuk kandang + Serbuk gergaji (1:1:1)) dan M7 ( Tanah + Pupuk kandang + Abu sekam padi (1:1:1)). Masing-masing perlakuan 60 bibit sehingga total bibit yang diperlukan adalah 7 x $60=420$ bibit. Hasil penelitian menunjukkan bahwa campuran media M4 (Tanah+ Pupuk kandang+Pasir $(1: 1: 1))$ memberikan pertumbuhan diameter $(0,469 \mathrm{~cm})$, tinggi $(22,678 \mathrm{~cm})$ dan jumlah daun $(9,978)$ M. glauca BI yang lebih baik dibanding media lainnya. Campuran media M5 (tanah+pupuk kandang+serbuk sabut kelapa (1:1:1)) memberikan berat kering akar $(2,096)$, berat kering batang dan daun $(4,046)$ dan indeks mutu bibit $(0,132)$ M. glauca BI yang terbaik dibanding media lainnya. Kesimpulan dari penelitian ini adalah penggunaan campuran media M4 dan M5 masing-masing memberikan pertumbuhan dan indeks mutu bibit yang terbaik dalam teknik pembibitan M. glauca BI.
\end{abstract}

Kata kunci : Indeks mutu bibit, Manglieta glauca BI dan media sapih 


\section{PENDAHULUAN}

\section{A. Latar Belakang}

Manglieta glauca BI merupakan salah satu jenis tanaman andalan setempat dan tergolong fast growing spesies sehingga banyak disukai petani hutan rakyat. Di Jawa Barat, manglid dikembangkan melalui agroforestry pada progam perhutanan sosial dan dijadikan komoditas unggulan dalam pengembangan hutan rakyat dalam rangka meningkatkan kesejahteraan masyarakat sekitar hutan (Rimpala, 2001). Pohon manglid dapat mencapai tinggi maksimum $40 \mathrm{~m}$ dengan garis tengah 150 $\mathrm{cm}$ dan mampu mencapai tinggi 4-6 $\mathrm{m}$ dalam waktu lima tahun (Hildebran 1935 dalam Rimpala, 2001). Di Jawa Barat jenis ini sangat disukai karena selain kayunya mengkilat, strukturnya padat, halus, ringan dan kuat, kekuatan kayunya digolongkan dalam kelas III dan keawetannya kelas II. Adapun keuntungan dari kayu manglid tersebut karena ringan yaitu dengan berat jenis (BJ) 0,41 sehingga mudah dikerjakan, sering dijadikan bahan baku pembuatan jembatan, perkakas rumah, barangbarang hiasan, patung dan ukiran dan ini banyak ditemukan di daerah Bali (Rimpala 2001). Kegunaan kayu manglid selama ini adalah sebagai daun pintu, perkakas rumah tangga (meja, kursi, almari), bangunan rumah, pembangunan jembatan, pelapis kayu dan plywood serta diharapkan dapat dijadikan bahan baku pulp (Prosea, 1998; Diniyati dkk., 2005).

Keberhasilan progam penanaman baik dalam rangka pembangunan hutan tanaman maupun rehabilitasi lahan terdegradasi diperlukan ketersediaan bibit berkualitas. Untuk menghasilkan bibit berkualitas diantaranya memerlukan media dengan komposisi bahan organik dan unsur hara yang diperlukan bagi tanaman (Durahim, 2001). Selain kandungan unsur hara diperlukan berbagai campuran di dalam media untuk meningkatkan porositas sehingga sesuai bagi pertumbuhan akar tanaman. Oleh karena itu campuran media yang mempunyai unsur hara dan porositas sekaligus menjadi pilihan dalam menghasilkan bibit berkualitas. Pada umumnya media yang digunakan untuk pembibitan berasal dari top soil dicampur pupuk kandang. Pengambilan top soil dalam skala besar dapat berdampak negatif bagi ekosistem di areal tersebut (Hendromono, 1994). Selain itu top soil di suatu daerah tidak selalu subur sehingga memerlukan campuran untuk menambah unsur hara, aerasi dan porositas media. Oleh karena itu dalam rangka menjaga ekosistem dan memperbaiki kualitas bibit diperlukan media yang merupakan campuran limbah bahan organik dan tanah.

Dalam pembangunan hutan tanaman, khususnya hutan rakyat maupun GNRHL, masih dijumpai kendala, dengan bibit yang ditanam memiliki kualitas pertumbuhan yang rendah diantaranya karena dari penggunaan media tumbuh semai yang berkualitas rendah. Media tumbuh semai yang dipergunakan pada persemaian di areal hutan tanaman, khususnya hutan rakyat pada umumnya hanya menggunakan tanah (top soil). Media semai tanah (top soil) tidak selalu mempunyai tingkat kesuburan yang baik sehingga diperlukan campuran bahan organik untuk menghasilkan bibit berkualitas. Ketersediaan berbagai limbah bahan organik, seperti serbuk gergaji, serbuk sabut kelapa, sekam padi dan kotoran hewan di sekitar lingkungan petani hutan rakyat sangat potensial digunakan sebagai media sapih dalam pembuatan bibit tanaman hutan. Masalahnya adalah pengetahuan petani tentang penggunaan berbagai limbah bahan organik tersebut sebagai media pertumbuhan semai masih terbatas. Oleh karena itu diperlukan dukungan IPTEK tentang penggunaan berbagai bahan organik sebagai media sapih untuk menghasilkan bibit $M$. glauca $B I$ berkualitas.

\section{B. Tujuan penelitian}

Tujuan penelitian ini adalah untuk mengetahui jenis media sapih yang mampu menghasilkan pertumbuhan dan mutu bibit Manglieta glauca BI yang terbaik.

\section{BAHAN DAN METODE}

\section{A. Lokasi dan Waktu Penelitian}

Penelitian dilakukan di persemaian Balai Penelitian Kehutanan Ciamis dari bulan Februari sampai dengan September 2008.

\section{B. Bahan dan Alat}

Bahan dan alat yang digunakan dalam penelitian ini adalah benih manglid, ayakan pasir, tampah, bak kecambah, tanah, pasir, serbuk sabut kelapa (coco peat), serbuk gergaji, abu sekam padi, sekam padi, polybag, kaliper, luxmeter, timbangan analitik,gembor, oven dan alat tulis. 


\section{Metode Penelitian}

Metode yang digunakan dalam penelitian ini diuraikan sebagai berikut.

\section{Penanganan Buah}

Ekstrasi benih atau cara mengeluarkan benih dari buah untuk manglid adalah dengan menjemur buah yang telah masak sampai pecah sehingga memudahkan mengeluarkan benihnya. Benih yang telah keluar dari kulit buah masih diselimuti daging buah sehingga perlu dibersihkan dengan cara menaruh benih dalam tempayan lalu menggosoknya dengan kain sehingga benih bersih dari daging buah, kemudian dicuci bersih dan dikeringanginkan dalam ruangan selama 2 jam.

\section{Perkecambahan}

Perkecambahan dilakukan dengan menabur benih yang telah dibersihkan sesegera mungkin agar tidak berkurang daya kecambahnya pada bak kecambah yang berisi media serbuk gergaji atau abu sekam padi. Penyiraman dilakukan sehari sekali menggunakan gembor.

\section{Penyapihan}

Penyapihan dilakukan pada kecambah yang telah memiliki rata-rata 3 daun. Media yang digunakan adalah:

M1 $=$ Tanah + Pupuk kandang $(3: 1)$

M2 = Tanah

M3 = Tanah + Pupuk kandang + Sekam padi $(1: 1: 1)$

M4 $=$ Tanah + Pupuk kandang + Pasir $(1: 1: 1)$

M5 = Tanah + Pupuk kandang + Serbuk sabut kelapa $(1: 1: 1)$

M6 = Tanah + Pupuk kandang + Serbuk gergaji $(1: 1: 1)$

M7 = Tanah + Pupuk kandang + Abu sekam padi $(1: 1: 1)$

\section{Pengamatan}

Pengukuran pertumbuhan bibit yaitu tinggi, diameter, jumlah daun, persen hidup bibit dilakukan setiap bulan sampai bibit berumur 4 bulan setelah penyapihan. Untuk mengetahui kualitas bibit secara fisiologis, maka dilakukan penghitungan Indeks Mutu Bibit (IMB) pada akhir pengukuran. Penghitungan indeks mutu bibit mengunakan cara Dickson (1960) dalam Kurniaty dkk (2007) dengan dengan rumus sebagai berikut:

$$
\mathrm{IMB}=(\mathrm{A}+\mathrm{B}) /(\mathrm{C} / \mathrm{D}+\mathrm{A} / \mathrm{B})
$$

Keterangan :

$\mathrm{IMB}=$ Indeks Mutu Bibit

$\mathrm{A}=$ Berat kering batang + daun $($ gram $)$

$\mathrm{B}=$ Berat kering Akar (gram)

$\mathrm{C}=$ Tinggi $(\mathrm{cm})$

$\mathrm{D}=\operatorname{Diameter}(\mathrm{cm})$

\section{Rancangan Penelitian}

Rancangan penelitian yang digunakan dalam penelitian ini adalah Rancangan Acak Lengkap (RAL) dengan 7 perlakuan. Masingmasing perlakuan 60 bibit sehingga total bibit yang diperlukan 7 × $60=420$ bibit. Pengamatan terhadap panjang akar, jumlah akar dan berat kering akar, berat kering batang+daun dan indeks mutu bibit pada masing-masing perlakukan diambil 10 sampel bibit sedangkan pada pengamatan survival dilakukan terhadap 20 bibit yang terdapat dalam 3 kelompok.

\section{E. Analisis Data}

Analisis yang digunakan untuk menguji variasi dari variabel yang diamati adalah analisis varian dengan menggunakan uji $\mathrm{F}$ dengan taraf 5\%. Selanjutnya apabila perlakuan berpengaruh nyata terhadap parameter yang diukur maka dilanjutkan dengan menggunakan uji Duncan (Sastrosupadi, 2000)

\section{HASIL DAN PEMBAHASAN}

Hasil analisis varian menunjukkan bahwa perlakuan media yang diuji berpengaruh nyata terhadap pertumbuhan diameter, tinggi, jumlah daun, persen hidup, berat kering akar, berat kering batang + daun dan indeks mutu bibit tetapi tidak berpengaruh nyata pada panjang dan jumlah akar seperti yang disajikan pada Tabel 1.

Dari hasil uji lanjut Duncan yang disajikan pada Tabel 2 terlihat bahwa media M4 (Tanah+Pupuk kandang+Pasir $(1: 1: 1))$ memberikan pertumbuhan diameter $(0,469 \mathrm{~cm})$, tinggi $(22,678 \mathrm{~cm})$ dan jumlah daun $(9,978)$ yang relatif lebih baik dibanding penggunaan media lainnya. Meskipun demikian media M4 memberikan persen hidup semai yang relatif lebih rendah yaitu $75 \%$ dan tidak berbeda nyata dengan M1 (90\%), M2 (91,7\%), M3 (91,7\%), M5 (81,7\%) dan M6 (78,3\%). Media M4 memberikan indeks mutu bibit $(0,071)$ yang berbeda nyata lebih rendah dengan M5 $(0,132)$ dan M7 (0,095). Hal ini menunjukkan bahwa penggunaan media M4 (Tanah+Pupuk 
Tabel(Table) 1. Hasil analisis varian pertumbuhan diameter, tinggi, jumlah daun, persen hidup, panjang akar, jumlah akar, berat kering akar, berat kering batang + daun dan indeks mutu bibit umur 4 bulan Manglieta glauca BI (The result of analysis varians on diameter, height, leave number, survival rate, root and stem + leave's biomass, and seedling quality index of 4 months old Manglieta glauca BI)

\begin{tabular}{|c|l|c|c|}
\hline No. & \multicolumn{1}{|c|}{$\begin{array}{c}\text { Parameter } \\
\text { (Parameter) }\end{array}$} & $\begin{array}{c}\text { F Hitung } \\
\text { (F Value) }\end{array}$ & $\begin{array}{c}\text { F Tabel } \\
\text { (F Table) }\end{array}$ \\
\hline 1 & Diameter $(\mathrm{cm})$ & $7,854^{*}$ & 2,14 \\
\hline 2 & Tinggi $(\mathrm{cm})$ & $33,742^{*}$ & 2,14 \\
\hline 3 & Jumlah daun & $3,904^{*}$ & 2,14 \\
\hline 4 & Persen hidup (\%) & $3,930^{*}$ & 2,85 \\
\hline 5 & Panjang akar & $2,238 \mathrm{~ns}$ & 2,25 \\
\hline 6 & Jumlah akar & $1,012 \mathrm{~ns}$ & 2,25 \\
\hline 7 & Berat kering akar & $14,332^{*}$ & 2,25 \\
\hline 8 & Berat kering batang+daun & $6,469^{*}$ & 2,25 \\
\hline 9 & Indeks mutu bibit & $19,795^{*}$ & 2,25 \\
\hline
\end{tabular}

Keterangan (Remark) :* : berbeda pada tingkat kepercayaan 95\% (significant at level of 95\%) dan ns : tidak berbeda nyata pada tingkat kepercayaan 95\% (nonsignificant at level 95\%)

kandang+Pasir (1:1:1)) akan memberikan pertumbuhan semai lebih baik tetapi dengan persen hidup dan indeks mutu bibit relatif kurang baik di banding media lainnya. Menurut Winarto (2003) bahwa pupuk organik biasanya mengandung unsur lengkap unsur hara yang dibutuhkan tanaman baik hara makro maupun mikro walaupun lambat diserap oleh tanaman. Input pasir dapat menjaga struktur tanah tetap remah dan gembur sehingga memperlancar pertumbuhan akar dalam menyerap unsur hara. Pada media tanah tanpa campuran pasir dan pupuk kandang lamakelamaan menjadi padat dan tidak gembur sehingga memperlambat pertumbuhan bibit. Dengan mencampur media tanah + pasir, menyebabkan aerasi dan drainase menjadi lebih baik, kemampuan mengikat air dan unsur hara juga lebih baik dibandingkan dengan media tanah atau media pasir. Sesuai dengan pendapat Buckman et al., (1982), bahwa pasir mempunyai daya aerasi dan draenase yang baik, tetapi sukar mengikat air dan miskin zat hara.

Tanah mempunyai daya mengikat air dan unsur hara yang baik, tetapi cenderung memiliki aerasi dan drainase yang kurang baik. Hal ini sesuai dengan penelitian Lendri (2003) menyatakan bahwa media tanah+pasir+kompos (1:1:1) memberikan persentase hidup yang tinggi dan kondisi bibit yang baik daripada campuran tanah+pupuk kandang (2:1) pada bibit mengkudu (Morinda citrifolia). Novizan (2005) dalam Kosasih dan Heryati (2006) mengatakan bahwa media yang baik mempunyai empat fungsi utama yaitu memberi usur hara dan sebagai media perakaran, meyediakan air dan tempat penampungan air, menyediakan udara untuk respirasi akar dan sebagai tempat bertumbuhnya tanaman.

Berat kering akar, berat kering batang dan daun dan indeks mutu bibit pada media M5 (tanah+pupuk kandang+serbuk sabut kelapa $(1: 1: 1))$ menunjukkan hasil yang terbaik dibanding media lainnya. Hal ini menunjukkan bahwa serbuk sabut kelapa memberikan keseimbangan pertumbuhan akar dengan pertumbuhan batang dan daun yang relatif lebih baik dibanding media lainnya. Dengan indeks mutu bibit yang lebih baik maka peluang keberhasilan penanaman di lapangan juga akan semakin besar. Pemilihan campuran media M5 akan sesuai untuk peningkatan kualitas bibit meskipun dengan pertumbuhan tinggi relatif lebih rendah dibanding M1, M3, M4, M6 dan jumlah daun yang relatif lebih rendah dibanding M2 dan M4. Hendromono (2004) melaporkan bahwa kompos sabut kelapa sawit + sekam padi 1 : $1(\mathrm{~V}: \mathrm{V})$ merupakan media yang sesuai untuk pembibitan Khaya anthoteca. Sementara 
Durahim (2001) menyimpulkan bahwa penggunaan media campuran top-soil + sekam padi + sabut kelapa 1:1:1 (V:V:V) meningkatkan pertumbuhan dan mutu morfologi bibit mahoni (Switenia macrophylla).

Campuran media M3 (Tanah+pupuk kandang+sekam padi (1:1:1)) memberikan pertumbuhan jumlah daun yang tidak berbeda nyata dengan M1, M2, M4 dan M6 tetapi berbeda nyata lebih baik dibanding M5 dan M7. Indriyanto (2003) melaporkan bahwa media tanah + bokashi sekam padi $(2: 1)$ memberikan hasil relatif lebih baik untuk pembibitan cengal (Hopea sangal Korth) dibandingkan tanah dan tanah + serbuk gergaji. Media sekam padi dapat menciptakan kondisi lingkungan tumbuh khususnya sifat fisik dan kimia tanah yang lebih baik bagi pertumbuhan tanaman karena lebih cepat proses pelapukan dan dekomposisi, mengandung unsur hara $\mathrm{N}, \mathrm{P}, \mathrm{K}, \mathrm{Cl}$ dan $\mathrm{Mg}$ (Thomas, 1995). Media tumbuh yang mengandung sekam, laju absorbsi $\mathrm{Ca}$ dan $\mathrm{Mg}$ lebih tinggi dibandingkan dengan yang lainnya. Erlan (2005) menyatakan bahwa urutan media yang relatif lebih baik untuk pertumbuhan mahkota dewa (Phaleria macrocarpha (Scheff.)
Boerl.) berturut-turut adalah tanah + kompos, tanah + serbuk gergaji dan tanah + sekam padi dibanding dengan tanah + pupuk kandang dan tanah tanpa campuran. Mahfudz dkk, 2005 menyatakan bahwa media tanah+kompos (1:1). menghasilkan bibit jati terbaik dibanding penggunaan tanah, tanah + sekam padi (1:1) dan tanah+pupuk kandang $(1: 1)$.

Walaupun media campuran M6 (Tanah + Pupuk kandang + Serbuk gergaji $(1: 1: 1))$ relatif mempunyai pertumbuhan yang relatif lebih lambat dibanding M4 dan M5, semai yang ditumbuhkan pada media yang mengandung serbuk gergaji cenderung mempunyai kandungan $\mathrm{K}$ yang paling tinggi (Sunantara dkk., 2005). Hal ini diduga ada kaitannya dengan kemampuan media tumbuh dalam menyediakan unsur-unsur hara tersebut selama pertumbuhan semai berlangsung seperti yang disajikan pada Lakitan (1995) menyatakan bahwa serbuk gergaji sedikit mengandung $\mathrm{N}, \mathrm{P}, \mathrm{K}$ dan $\mathrm{Mg}$ dengan kapasitas penyangga baik dan kapasitas pegang/pengikat air baik sampai sangat baik walaupun sulit terdekomposisi karena kandungan kimia (lignin, hemiselulosa dan lain-lain) dan zat ekstratif yang mengganggu pertumbuhan cendawan.

Tabel (Table) 2. Hasil uji lanjut Duncan pengaruh komposisi media sapih terhadap diameter, tinggi, jumlah daun, persen hidup, berat kering akar, berat kering batang + daun dan indeks mutu bibit Manglieta glauca BI pada umur 4 bulan (The result of Duncan advanced test on the influence of replanting media composition on diameter, height, leave number, survival rate, root and stem + leave's biomass, and seedling quality index of 4 months old Manglieta glauca $B I$ )

\begin{tabular}{|c|c|c|c|c|c|c|c|}
\hline $\begin{array}{c}\mathrm{M} \\
\mathrm{e} \\
\mathrm{d} \\
\mathrm{i} \\
\mathrm{a}\end{array}$ & $\begin{array}{c}\text { Diameter/ } \\
\text { Diameter } \\
(\mathrm{cm})\end{array}$ & $\begin{array}{l}\text { Tinggi } \\
\text { /Height } \\
(\mathrm{cm})\end{array}$ & $\begin{array}{c}\text { Jumlah } \\
\text { daun / } \\
\text { Leave } \\
\text { number }\end{array}$ & $\begin{array}{l}\text { Persen } \\
\text { hidup / } \\
\text { Survival } \\
\quad(\%)\end{array}$ & $\begin{array}{c}\text { Berat } \\
\text { kering } \\
\text { akar /Root } \\
\text { biomass } \\
\text { (gr) }\end{array}$ & $\begin{array}{l}\text { Berat kering } \\
\text { batang }+ \\
\text { daun / } \\
\text { stem+leave's } \\
\text { biomass } \\
\text { (gr) }\end{array}$ & $\begin{array}{l}\text { Indeks } \\
\text { mutu } \\
\text { bibit / } \\
\text { seedling } \\
\text { quality } \\
\text { index }\end{array}$ \\
\hline M1 & 0,427 bcd & $18,833 \quad$ c & 9,352 bc & $90,0 \quad \mathbf{b}$ & $0,845 \mathbf{a b}$ & $2,753 \mathbf{b}$ & $0,056 \mathbf{b c}$ \\
\hline M2 & $0,333 \mathbf{a}$ & $11,364 \mathbf{b}$ & $9,673 \quad \mathbf{c}$ & $91,7 \mathbf{b}$ & $0,450 \mathbf{a}$ & $1,170 \mathbf{a}$ & $0,030 \mathbf{a}$ \\
\hline M3 & $0,41 \quad \mathbf{b}$ & $18,955 \quad \mathbf{c}$ & $9,200 \mathbf{b c}$ & $91,7 \quad \mathbf{b}$ & $0,695 \mathbf{a b}$ & $2,074 \mathbf{a b}$ & $0,042 \mathbf{a b}$ \\
\hline M4 & $0,469 \quad \mathbf{d}$ & 22,678 & $9,978 \quad \mathbf{c}$ & $75,0 \quad \mathbf{b}$ & $1,096 \mathbf{b c}$ & $2,624 \mathbf{b}$ & $0,071 \quad$ c \\
\hline M5 & 0,433 cd & $13,388 \mathbf{b}$ & $8,551 \mathbf{a b}$ & $81,7 \quad$ b & 2,096 & $4,046 \quad \mathbf{c}$ & 0,132 \\
\hline M6 & $0,379 \mathbf{a b}$ & $17,000 \quad \mathbf{c}$ & 9,234 bc & 78,3 b & 1,474 cd & $4,214 \quad \mathbf{c}$ & 0,072 c \\
\hline M7 & $0,34 \mathbf{a}$ & $8,953 \mathbf{a}$ & $8,063 \mathbf{a}$ & $53,3 \mathbf{a}$ & 1,764 de & $3,171 \mathbf{b c}$ & 0,095 \\
\hline
\end{tabular}

Keterangan(Remark) : Nilai yang diikuti dengan huruf yang sama dalam suatu kolom menunjukkan tidak berbeda nyata pada tingkat kepercayaan 95\% (Value followed by same letter on column indicated not different at level 95\%) 
Tabel (Table) 3. Hasil analisis sifat fisik dan kimia serbuk sabut kelapa.(The analysis result on physical and chemical characteristics of cocopeat)

\begin{tabular}{|l|l|l|l|l|l|l|l|l|l|l|l|l|}
\hline No & Seri & \multicolumn{3}{|c|}{ Tekstur } & \multicolumn{3}{l|}{ Ekstrak 1:5 } & \multicolumn{3}{l|}{ Terhadap contoh kering $105^{\circ} \mathrm{C}$} \\
\hline & & Pasir & Debu & Liat & \multicolumn{2}{|c|}{$\mathrm{pH}$} & \multicolumn{3}{c|}{ Bahan organik } & & \\
\hline & & & & & $\mathrm{H} 20$ & $\mathrm{KCL}$ & $\begin{array}{c}\text { Walkley\&Black } \\
\mathrm{C}\end{array}$ & $\begin{array}{c}\text { Kjeldahl } \\
\mathrm{N}\end{array}$ & $\begin{array}{l}\mathrm{C} / \mathrm{N} \\
\text { Olsen } \\
\text { P2O5 }\end{array}$ & $\begin{array}{l}\text { Morgan } \\
\text { K2O }\end{array}$ \\
\hline 1 & Cocopeat & 0 & 35 & 65 & 6,1 & 5,0 & 47,05 & 0,81 & 58 & 412 & 13896 \\
\hline
\end{tabular}

Sumber (Source): Hasil analisis data primer di Balai Penelitian Tanah Bogor (The result of analysis primary data at Bogor Soil Research Institute)

Penambahan pupuk kandang, sekam maupun serbuk gergaji dapat menurunkan bobot jenis isi (BI) dan bobot jenis partikel (BJP), tetapi meningkatkan porositas, air tersedia, pori drainase cepat dan lambat (Sunantara dkk, 2005). Penambahan bahan organik menyebabkan jarak antar partikel tanah semakin besar dan terisi oleh hasil dekomposisi. Dibandingkan sekam dan serbuk gergaji, pupuk kandang dapat menciptakan granulasi media tumbuh lebih baik, sehingga tercipta struktur media yang baik pula. seperti yang ditunjukkan dengan persen pori drainase cepat yang lebih kecil atau jumlah pori makro yang lebih sedikit. Hal ini berkaitan erat dengan kandungan lignin dan hypoprotein yang relatif resisten terhadap pelapukan yang berturut-turut dari tertinggi pada serbuk gergaji, sekam dan pupuk kandang. Supardi (1983) menyatakan bahwa 0,2\% bagian kotoran sapi merupakan jaringan jasad yang berperan penting dalam aktivitas biologi.

Black (1946) menambahkan bahwa kemampuan media tumbuh dalam menunjang pertumbuhan akar yang baik, juga tergantung pada distribusi ukuran pori dan aktivitas jasad mikro. Tingkat $\mathrm{pH}$ media tumbuh yang menggunakan pupuk kandang relatif lebih rendah dibandingkan yang menggunakan sekam maupun serbuk gergaji karena asam-asam humid yang dilepaskan oleh jasad mikro. Kenyataan ini menunjukkan bahwa proses dekomposisi bahan organik dari pupuk kandang berlangsung lebih awal daripada sekam dan serbuk gergaji. Proses dekomposisi akan meningkat seperti ditunjukkan dengan menurunnya nilai bandingan $\mathrm{C} / \mathrm{N}$ (Supriyanto dan Ernawanto, 1986).

Dalam proses mineralisasi ini, kationkation akan segera dilepas, sehingga $\mathrm{pH}$ pada akhir pengamatan menjadi lebih besar. Proses mineralisasi bahan organik akan terjadi bila bandingan $\mathrm{C} / \mathrm{N}<25$ (Anonim, 1984 dalam Sunantara dkk, 2005). Media tumbuh yang mengandung pupuk kandang memiliki sifat fisik dan kimia yang lebih mantap, sehingga mampu menunjang pertumbuhan perakaran dan semai lebih baik. Semai yang ditumbuhkan pada media yang mengandung pupuk kandang cenderung mempunyai laju absorbsi $\mathrm{N}$ dan $\mathrm{P}$ lebih tinggi. Berdasarkan hasil analisa sifat fisik dan kimia, media tumbuh yang mengandung pupuk kandang mempunyai sifat-sifat fisik dan kimia sebagai berikut. BI 0,90-1,22 g/ $\mathrm{cm}^{3}$. BJP 2,25-2,31 g/ $/ \mathrm{cm}^{3}$, porositas $46,94-59,85 \%$, air tersedia $6,75-$ $17,13 \%$ pori drainase cepat $23,03-30,24$ dan pori drainase lambat 1,72-2,88; $\mathrm{pH} \quad\left(\mathrm{H}_{2} \mathrm{O}\right)$ berkisar 7,2-7,5 dan $\mathrm{pH}(\mathrm{KCl})$ 6,3-6,6 serta bandingan C/N 9,4-18,6 (Sunantara dkk, 2005).

Media M7 memberikan hasil pertumbuhan diameter, tinggi, jumlah daun dan persentase hidup bibit Manglieta glauca BI terjelek dibanding media lainnya, hal ini dikarenakan bibit banyak terserang penyakit rebah semai/ dumping off. Penggunanaan abu sekam padi juga bukan merupakan tambahan unsur hara tetapi dapat meningkatkan $\mathrm{pH}$, aerasi dan porositas media. Mengingat dumpig off banyak terjadi pada persemaian yang terlalu lembab dan media yang dapat meningkatkan $\mathrm{pH}$, maka kelembaban dari persemaian hendaknya dijaga jangan sampai tinggi dan usahakan adanya cukup sinar matahari yang masuk serta hindari penggunaaan media yang dapat meningkatkan $\mathrm{pH}$ seperti abu sekam padi. Penggunaan abu sekam padi sebagai campuran media dapat menaikkan $\mathrm{pH}$ dan kelembaban sehingga kondusif bagi patogen dumping off. Penggunaan arang sekam padi akan lebih baik karena butiran bersifat lebih besar dan kasar sehingga akan memperbaiki aerasi dan porositas media tanpa menaikkan $\mathrm{pH}$ secara lebih besar dibanding abu sekam padi. Hasil penelitian Kurniaty dkk. (2007) menunjukkan hasil yang berbeda pada media tanah + arang sekam padi (1:1) dengan pertumbuhan tinggi, diameter dan persen hidup bibit mindi (Melia azedaract) terbaik dibanding dengan media tanah, sabut kelapa, arang sekam padi+sabut kelapa (1:1) dan tanah +sabut kelapa (1:1) sampai umur 5 bulan. Hal ini menunjukkan bahwa setiap jenis tanaman memerlukan kondisi media penyapihan yang berbeda untuk dapat menghasilkan pertumbuhan dan mutu bibit yang lebih baik. 


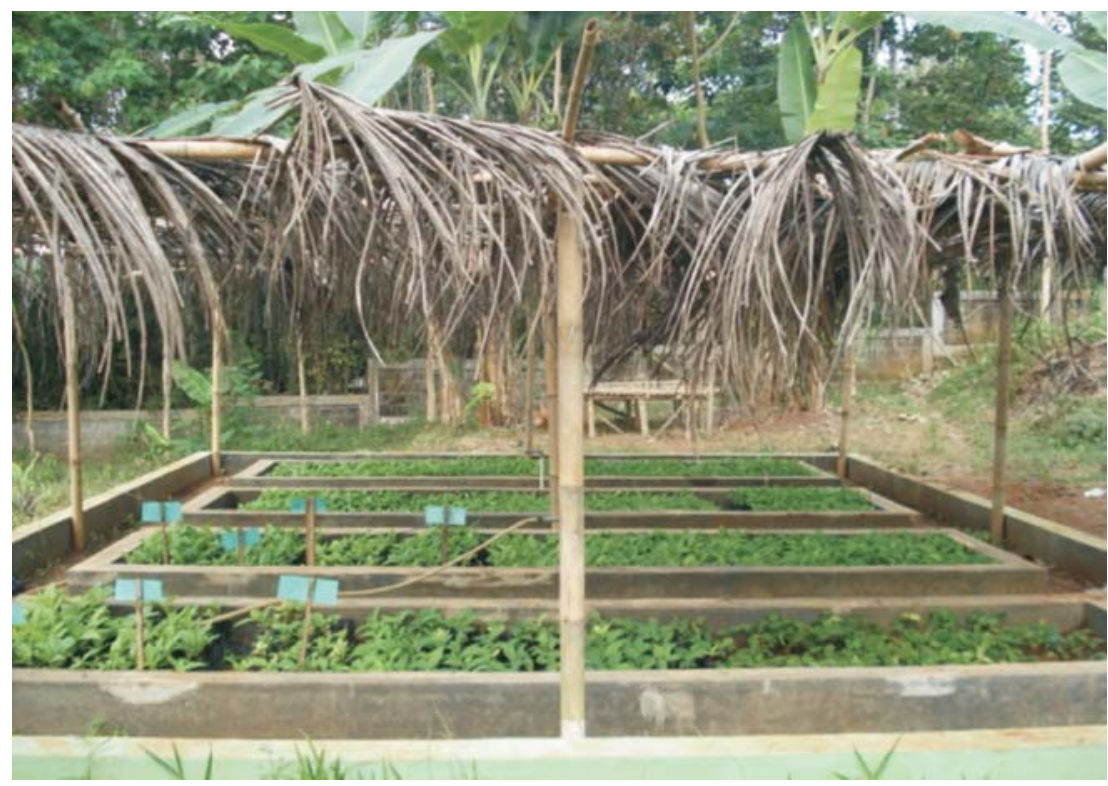

Gambar(Figure) 1. Kenampakan bibit Manglieta glauca BI umur 2 bulan (Performance of seedling Manglieta glauca BI at 2 months old)

\section{KESIMPULAN}

1. Perlakuan 7 jenis media sapih pada tanaman manglid memberikan respon yang berbeda nyata terhadap pertumbuhan diameter, tinggi, persen hidup, berat kering akar, berat kering batang+daun dan indeks mutu bibit.

2. Pertumbuhan diameter, tinggi dan jumlah daun bibit manglid yang terbaik adalah menggunakan campuran media tanah + pupuk kandang + pasir (1:1:1) yaitu sebesar 0,469 $\mathrm{cm}, \quad 22,678 \mathrm{~cm}$ dan 9,978, sedangkan persentase hidup bibit manglid terbaik sebesar 91,7\% dihasilkan pada campuran media sapih tanah + pupuk kandang+sekam padi $(1: 1: 1)$ dan terendah sebesar 53,3\% pada campuran media tanah + pupuk kandang + abu sekam padi $(1: 1: 1)$.

3. Campuran media tanah + pupuk kandang + serbuk sabut kelapa (1:1:1) menghasilkan indeks mutu bibit manglid terbaik yaitu sebesar 0,132 sedangkan indeks mutu bibit terendah dihasilkan pada campuran media sapih tanah + pupuk kandang + sekam padi (1:1:1) yaitu sebesar 0,042 .

\section{DAFTAR PUSTAKA}

Buckman, H.O., and N.C.Brady. 1982. Ilmu Tanah. Bhatara Karya Aksara. Jakarta. 788 hal.
Diniyati, D. Suyarno, D.P. Kuswantoro, A. Badrunasar, E. Fauziyah, T. Sulistyati, dan E. Mulyati. 2005. Teknik Perbanyakan Tanaman Manglid (Manglieta glauca BI) dengan Biji. Loka Penelitian dan Pengembangan Hutan Monsoon. Ciamis

Durahim dan Hendromono, 2001. Kemungkinan Penggunaan Limbah Organik Sabut Kelapa Sawit dan Sekam Padi sebagai Campuran Top Soil untuk Media Pertumbuhan Bibit Mahoni (Swictenia macrophylla King). Buletin Penelitian Hutan no. 628 Hal 13-26

Erlan, 2005. Pengaruh Berbagai Media terhadap Pertumbuhan Bibit Mahkota Dewa (Phaleria macrocarpha (Scheff.) Boerl.) di Polibag. Jurnal Akta Agrosia Vol. 7 No.2 hlm 72-75 Jul - Des 2005 ISSN : 1410-3354 Sekolah Tinggi Ilmu Pertanian Sriwigama. Palembang. Tanggal Akses 15 November 2008

Hendromono, 1994. Pengaruh Media Organik dan Tanah Mineral terhadap Mutu Bibit Pterygota alata Roxb. Buletin Penelitian Hutan no 617:55-64

Hendromono dan Durahim, 2004. Pemanfaatan Limbah Sabut Kelapa Sawit dan Sekam Padi sebagai Medium Pertumbuhan Bibit Mahoni Afrika (Khaya anthoteca C. DC). Buletin Penelitian Hutan No 644. Badan 
Litbang Kehutanan. Puslitbang Hutan dan Konservasi Alam. Bogor.

Indriyanto, 2003. Laporan Penelitian Respon Semai Pohon Cengal (Hopea sangal Korth) terhadap campuran media tanah, bokashi sekam padi dan Bokhasi serbuk kayu gergaji di Persemaian. Universitas Lampung.

Kurniaty, R., B. Budiman dan M. Suartana. Pengaruh Media dan Naungan terhadap Mutu Bibit Mindi. 2007. Buletin Puslitbang Volume X No 02 Oktober 2007. Cepu

Lakitan, B. 1995. Fisiologi Pertumbuhan dan Perkembangan Tanaman. PT. Raja Grafindo Persada, Jakarta.

Lendri, S. 2003. Buletin Teknik Pertanian Vol 8. Nomor 1, 2003. Bogor.

Mahfudz, H. Supriyo, Suryanaji dan H. Supriyanto. 2005. Pengaruh Penggunaan Biostimulan, Jenis dan Volume Media terhadap Pertumbuhan Semai Jati. Pusat Penelitian dan Pengembangan Hutan Tanaman. Yogyakarta.

Rimpala, 2001. Penyebaran Pohon Manglid (Manglietia Glauca BI.) di Kawasan
Hutan Lindung Gunung Salak. Laporan Ekspedisi Manglid. www.rimpala.com. Bogor.

Sastrosupadi, A. 2000. Rancangan Percobaan Praktis Bidang Pertanian. Penerbit Kanisius, Yogyakarta

Supriyanto, A. dan Ernawanto. 1986. Media Tumbuh untuk Pembibitan Jeruk. Buletin Tanaman Hortikultura XIV Edisi Khusus 23.

Sunantara,M., I.B. Aribawa dan I.K. Kariada, 2005. Pengaruh Berbagai Media Tumbuh terhadap Pertumbuhan Bibit Jeruk Bali (Citrus maxima. Merr). Balai Pengkajian Teknologi Pertanian (BPTP). Bali. Tanggal Akses 15 November 2008

Kurniaty, R., B. Budiman, dan M. Suartana 2007. Pengaruh Media dan Naungan Terhadap Mutu Bibit Mindi. Buletin Puslitbang Volume X No. 02 Oktober 2007 hal 668677. Cepu.

Kosasih, A.S., 2006. Pengaruh Medium Sapih terhadap Pertumbuhan Bibit Shorea selanica BI di Persemaian. Jurnal Hutan dan Konservasi Alam. Pusat Penelitian dan Pengembangan Hutan dan Konservasi Alam. Bogor 